\title{
Murder: Effects of number of killers and victim mutilation on simulated jurors' judgments
}

\author{
CLYDE HENDRICK \\ Kent State University, Kent, Ohio 44242 \\ and \\ DAVID R. SHAFFER \\ University of Georgia, Athens, Georgia 30601
}

\begin{abstract}
Simulated jurors read a brief transcript of a jury trial involving a victim who had been beaten to death by either one or five killers. For half of the subjects in each condition, further information was given that the victim's body was mutilated after death. Subjects assigned prison sentences and rated the crime and defendants on several scales. Results showed that murder followed by mutilization increased the severity of prison sentences by about 50 years. Attributions of insanity, evil nature of the crime, and attitude toward the death penalty also varied in an orderly manner as a result of the mutilation manipulation. It was concluded that simulated jury trials provide an excellent method for studying personal causation and attribution processes in general.
\end{abstract}

The social psychology of the trial jury is a research area of rapidly growing interest. Most of the studies use simulated juries and rating instruments, although social scientists are becoming increasingly influential in the actual trial court (e.g., Etzioni, 1974; Rokeach \& Vidmar, 1973).

One area of interest concerns the variables which affect simulated jurors' inferences of guilt and sentencing behavior. Some interesting findings have emerged; for example, that attitude similarity between defendant and jurors (Griffitt \& Jackson, 1973) and juror authoritarianism (Mitchell \& Byrne, 1973) affect jurors' certainty of guilt and severity of sentencing. Also, certain types of pretrial publicity may increase inferences of guilt (Hoiberg \& Stires, 1973).

The present experiment was concerned with another variable which might well affect juror attributions-the heinousness of a murder. Much of the fanfare of daily crime news consists of lurid details of murders. There seems to be considerable fascination by the public at large with violent murder as witnessed by a steady diet of pulp magazines, detective stories, and movies. Indeed, professional analyses seem unable to escape the need for gory detail (e.g., Ellis \& Gullo, 1971).

Journalistic sensation-seeking appears strongest for some combination of murder and mutilation, especially bodily dismemberment. Public revulsion seems strongest for the latter. A neat bullet hole near the base of the brain may merit only a couple of lines of newspaper space, but, if after shooting his victim, the killer then proceeds to cut off the victim's head, he is virtually

Requests for reprints should be addressed to Clyde Hendrick, Department of Psychology, Kent State University, Kent, Ohio 44242. guaranteed much more news space.

The process of fascination-revulsion with mutilation may well inflame juror opinion, resulting in much harsher sentences than for ordinary murders. Hoiberg and Stires (1973) found that simulated female jurors exposed to lurid pretrial publicity were more certain of guilt than subjects not so exposed, even though actual information in the simulated trial was the same in both conditions. In a similar way, a juror's knowledge of the heinous nature of a murder during the course of a trial might predispose him toward a guilty verdict and a harsher sentence.

The focus of the present study was restricted to sentencing behavior of simulated jurors as a function of whether a murder by beating was or was not followed by mutilation. In strict legal terms, homicide by beating is one crime, and the penalty is determined by the degree of premeditation. Mutilation of an already dead corpse is probably also a crime in most states but would not, per se, be nearly as serious as the basic fact of homicide. Despite the niceties of such legal distinctions, the strong association of murder plus mutilation should cue off strong emotional reactions from jurors, leading to much harsher sentences than when mutilation did not occur. The basic prediction, then, was that, assuming guilt of the accused, simulated jurors would pass more severe sentence for a murder followed by mutilation than for a murder without mutilation.

Mutilation of a victim seems to be often associated in the public mind with insanity ("only a crazy person would cut up a corpse like that"). Also, the context of inference is drastically shifted, depending on whether the murder is committed by a single killer or a group of several killers. If a lone killer dismembers the corpse, he 
may be adjudged insane, and the jury may moderate its sentence to some extent, taking that fact into account. However, if the murder is committed by five killers, the jury may be much more ambivalent about viewing the group per se as insane. There may be exceptions if the defendants behave badly enough at the trial (e.g., the Manson case). However, in general, a murder-mutilation by a group is more likely to be perceived as arising out of an evil set of group norms. Instead of insanity, the group is likely to be viewed as evil. Consequently, sentence for murder plus mutilation should be harsher when committed by a group than by a lone individual.

\section{METHOD}

\section{Design and Overview}

The experiment was a 2 by 2 factorial between-groups design. Subjects read a brief trial transcript in which a victim was beaten to death by either one man or five men. For half the subjects within each condition, the transcript stopped at this point. For the other half of the subjects, an additional paragraph described the mutilation of the victim's body. The four conditions were: one killer-no mutilation, one killer-mutilation, five killers-no mutilation, and five killers-mutilation.

After reading the transcript, subjects completed a dependent variable form which included passing a prison sentence and answering several rating questions.

\section{Subjects}

Students from an introductory psychology class served as subjects in a large testing session. Each condition included males and females in roughly equal proportions, but no attempt was made to retain sex as a variable. A total of 200 students participated, but 8 returned unusable questionnaires, leaving a total of 192 subjects, distributed as follows: one killer-no mutilation, 39; one killer-mutilation, 50; five killers-no mutilation, 54; five killers-mutilation, 49. Subjects were randomly assigned to the four conditions.

\section{Procedure}

Subjects received experimental booklets in large manila envelopes. The first page was labeled "The Jury Project," and contained the instructions. It was noted that there is much concern at the present time because of overcrowded court schedules. As a consequence, courts in many states are trying new experimental procedures, such as videotaped testimony. The specific purpose of the present project was to find out if reading short summaries of trials lead to the same conclusion as hearing the full trial.

The logic of the experiment was thus presented to subjects as a search for a device to shorten jury trials. Further instructions asked the subjects to take the role of an experimental juror, pass sentence, and make judgments about the case. Subjects were asked to "try to take the mental set of a juror, and imagine that your decisions do have real consequences. In this way, we can validly compare your decision with that of real juries."

The second page of the booklet presented a fabricated transcript of a murder trial. As preliminary, subjects were informed that the case was heard by a regular 12-person jury, that the verdict was guilty, and in the state where the case was tried that the jury also had to set the sentence. The manipulation of one vs. five killers was included in this second page of "factual evidence." The transcript is given as follows, with the manipulation of number of killers inserted as appropriate:

On June 11, 1969 Charles Weaver was on his way home from work. Weaver was an accountant, 37 years old, married, and had two children. On the day in question he had worked late to finish a project, and left the office at approximately 8:15 p.m. He stopped at a drugstore to make a purchase. As he was leaving the drugstore he was engaged in a conversation by (John Doe)(five men, John Doe 1, 2, 3, 4, 5). Apparently Weaver and (Doe)(the five men) walked into a dimly lit alley behind the drugstore. The facts were never ascertained clearly, but for some reason (Doe)(the five Does) began to yell at Weaver, cursing and threatening him. (Doe)(They) then brutally assaulted Weaver, beating him with (his)(their) fists and a blunt metal object. Because of the severity of the beating, Weaver died immediately, suffering from a crushed skull and numerous internal injuries. Someone in the drugstore heard the commotion and called the police. The police arrived on the scene and arrested (Doe)(all five John Does) for murder.

For subjects in the no-mutilation condition, the transcript ended at this point; and subjects completed the dependent variable form. Subjects in the mutilation condition received an additional paragraph on a third page of the booklet. Wording varied slightly depending upon whether the murder was committed by one or five men.

When the police arrived on the scene, they witnessed a grisly sight. After (Doe)(the five Does) beat Weaver to death (he)(they)dismembered the corpse with (a large knife)(large knives) in (his)(their) possession. In particular, (he)(they) cut off the head and both hands, and (he)(one of the men) was holding the head by the hair when the police arrived. The motive for the dismemberment was not established at the trial. One officer testified that (Doe)(one John Doe) had rather incoherently stated that "the_deserved it." Another officer testified that (Doe)(another Doe) said (he)(they) did it just for kicks.

\section{Rating Form}

The rating form, entitled "Juror Verdict Questionnaire" consisted of several rating questions and an item requesting a sentence of years in jail. The latter item was phrased as follows:

As a juror you must decide on the length of the prison sentence to be passed. In the state where the crime occurred the minimum sentence is 5 years and the maximum is 99 years. The jury may settle on any number of years between these two extremes. In your judgment what is the appropriate length of the sentence?

Immediately following, subjects then filled in the item "I think the sentence should be a prison term of _ years."

The other items were each rated on a 5-point scale with appropriate end labels and, in some cases, center labels as well. These items were: (1) Would you recommend parole at some time in the future? (2) How horrible would you rate the crime? (3) To what extent do you believe the murder was due to insanity? (4) If the death penalty could be imposed in this case, would you be in favor of a death sentence? (5) To what extent would you classify the murder as a morally evil act? (6) To what extent do you think the murder was intentionally committed? (7) Were you able to infer any motive for the murder?

In addition, a manipulation check question asked how many men were involved in the murder, with, response alternatives ranging from 1 to 5 . Finally, subjects were asked to write a sentence or two describing their reactions to the case.

\section{RESULTS}

The summary statistics and analyses of variance are given in Table 1. 
Table 1

Means and Analyses of Variance

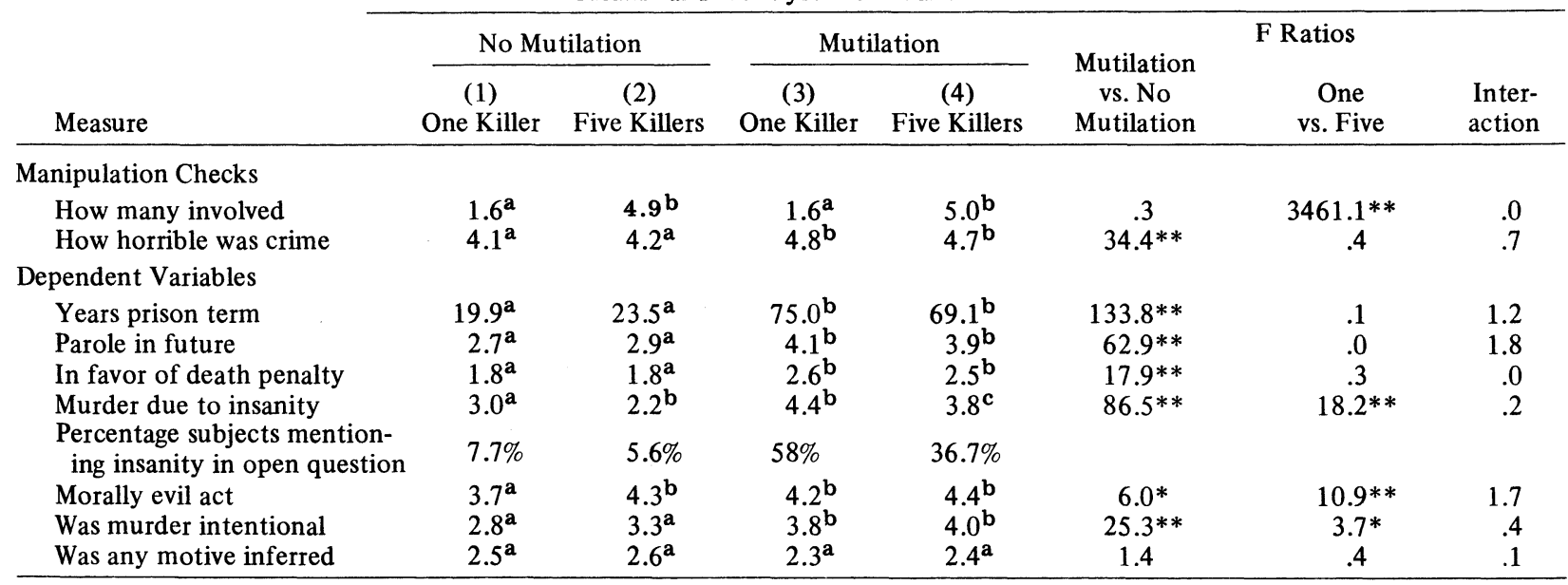

Note. Means with no superscripts in common differed at the .05 level by the Newman-Keuls test for comparisons 1 vs. 2,3 vs. 4,1 vs. 3, and 2 vs. 4 .

${ }^{*} p<.05$ **p $<.01$

\section{Manipulation Checks}

The results for the question asking how many men were involved in the murder indicated that this manipulation was successful. The means were 1.6 and 1.6 when one killer was involved and 4.9 and 5.0 when five killers were involved $(F=3,461.1 ; d f=1 / 188$; $\mathrm{p}<.01$ ). Some slight ambiguity was involved in this question because several subjects in the one-killer condition rated two men as involved, meaning both the killer and the victim.

The rating question on the horribleness of the crime was considered as a check on the mutilation manipulation. The means were 4.8 and 4.7 in the two mutilation conditions, but 4.1 and 4.2 in the two no-mutilation conditions $(\mathrm{F}=34.4, \mathrm{p}<.01)$. Both variables were adequately manipulated.

\section{Dependent Measures}

The main measure was the number of years subject jurors sentenced the killer or killers to prison. These scores could range from 5 to 99 years. 1 The only significant effect was due to the mutilation variable $(\mathrm{F}=133.8, \mathrm{p}<.05)$. Average sentences were 75.0 and 69.1 years in the two mutilation conditions, but 19.9 and 23.5 years in the two no-mutilation conditions. When mutilation occurred after the murder, subjects added about 50 years to the sentence! Clearly, this hypothesized result was overwhelmingly confirmed.

It was expected that the sentence for five killers who mutilated would be more severe than for one killer who mutilated. This expectation was not confirmed and may well have been due to an end effect in the scale. A considerable number of subjects in both the one- and five-killer mutilation conditions chose the most extreme alternative, 99 years. One has the impression that in the grand style of some Texas juries of recent years, many of the subjects would have passed a sentence of 10,000 years if that had been an option on the response scale.

This extreme response in sentencing was also reflected in several other dependent variables. Subjects tended not to want mutilators released on parole (the higher the score, the more against parole), with only a significant main effect of the mutilation variable $(F=62.9$, $\mathrm{p}<.01)$. Interestingly, in the mutilation conditions, subjects showed a significantly more favorable attitude toward the death penalty (2.6 and 2.5$)$ than in the no-mutilation conditions $(1.8$ and $1.8 ; \mathrm{F}=17.9$, $\mathrm{p}<.01)$.

The item assessing insanity was of particular interest. Both main effects were significant for this item. A single killer was judged as more likely insane than a group of five killers $(F=18.2, p<.01)$, and mutilators were viewed as more likely insane than nonmutilators $(\mathrm{F}=86.5, \mathrm{p}<.01)$. This result was also paralleled by the number of subjects spontaneously mentioning insanity in their written comments. These percentages are shown in Table 1.

If a group of killers is not as likely to be judged insane as a single killer, the process of attribution of cause will undoubtedly point in some other direction. In everyday life, one such other direction is the concept of evil. Five killers were rated as more morally evil than one killer $(\mathrm{F}=10.9, \mathrm{p}<.01)$, and, as expected, mutilation was rated as more evil than mere murder without mutilation $(F=6.0, p<.05)$.

With respect to perceptions of intentionality, subjects perceived greater intentionality for the murder when mutilation occurred $(\mathrm{F}=25.3, \mathrm{p}<.01)$. This result was somehwat surprising, particularly in view of subjects' written comments concerning the "senseless" nature of 
the act. No clear explanation for this effect was readily available. In addition, the main effect of one vs. five killers was marginally significant $(F=3.7, p=.052)$. Intentionality was perceived as higher when the crime was committed by five men.

Finally, there were no differences across conditions in subjects' ability to infer a motive for the murder. This outcome is desirable from the standpoint of explaining the data because significant effects would have posed possible alternative explanations for some of the other data (e.g., a stronger inference of motive in the mutilation condition might have led to the longer sentences rather than emotional revulsion toward the act).

\section{DISCUSSION}

Several aspects of the data deserve brief comment. First of course were the powerful effects of the mutilation manipulation. Such effects were expected, although not in such intensity. Certain aspects of the data were not precisely as expected. In particular, different inferences about insanity across conditions occurred as expected, but such variations seemed not to moderate sentencing. However, as noted above, mean sentence assignment may have been affected slightly by a scale end effect.

In another sense, however, the scenario of the trial made it difficult for subjects to take insanity into account when assigning prison terms. Instructions stated that the defendant(s) were found guilty. No mention of an insanity pleas was made in the transcript, and subjects were not given the response option of "not guilty by reason of insanity." Thus, prison sentences varied only in response to the mutilation variable.

In general, the trial transcript was quite sketchy and ambiguous, and purposefully so. An attempt was made to capture the essence of the manipulations, uncluttered by such variables as extenuating circumstances, victim liability, previous acquaintance with victim, etc. Ultimately, manipulation of these many variables will be desirable; however, in this initial study, allowing such variables a residual background ambiguity seemed a reasonable first step. For purposes of generalization to a real jury situation, however, it must be kept in mind that many other variables are operative. For example, in an actual murder-mutilation case, the jury might well ignore an insanity plea and find the defendant guilty. However, it seems unlikely that juries would consistently give sentences 50 years longer than when no mutilation occurred. Presumably, additional facts revealed in the courtroom, the defense attorney's plea, and the judge's charge to the jury, as well as other variables should moderate severity of the sentence. Despite such specific effects, however, the general principle will probably hold; namely, that juries are (assuming conviction) more punitive when bodily mutilation occurs.

Because of the sketchiness of the trial transcript, subjects voiced complaints in their written comments about lack of enough evidence. These complaints varied systematically across conditions. Under no mutilation, $51 \%$ of the subjects in the one-killer condition and $44 \%$ in the five-killer condition voiced such complaints. However, to borrow a phrase from Heider, the additional information about mutilation seemed to "engulf the field," reducing complaints of lack of information to $10 \%$ in the one-killer and $14 \%$ in the five-killer conditions. Subjects may have still puzzled about some specific bit of information, but given the mutilation paragraph, they certainly did not feel lacking for information in general. It may well be that information with an emotional impact seems more informative to subjects even though it objectively is not.

Subjects' written comments also revealed great concern with a variety of specifics, including such items as whether the victim knew the killer previously, whether the victim might be partially at fault, the content of the discussion prior to the murder, etc. Perceived causation in matters of law seems to have a very complex logic (Hart \& Honore, 1959) which rests squarely on the common sense psychology of everyday life which Heider (1958) attempted to explicate.

Following upon this fact, the study of simulated jury trials seems an excellent method for studying causal attribution and assignment of responsibility, as well as the more pragmatic possibility of generalizing to real jury settings. In their monumental work, Causation in the Law, Hart and Honore (1959) discuss in great detail many facets of what social psychologists call causal attributions. Application of experimental methods to Hart and Honore's insights should prove very fruitful in understanding attribution processes.

\section{REFERENCES}

Ellis, A., \& Gullo, J. M. Murder and assassination. New York: Stuart, 1971.

Etzioni, A. Social science in the jury box. The Plain Dealer, Cleveland, Ohio. June 7, 1974, 5-B and June 8, 1974, 5-B.

GriffitT, W., \& Jackson, T. Simulated jury decisions: The influence of jury-defendant attitude similarity-dissimilarity. Social Behavior and Personality: An International Journal, 1973, 1, 1-7.

Hart, H. L. A., \& Honore, A. M. Causation in the law. Oxford: Oxford University Press, 1959.

HEIDER, F. The psychology of interpersonal relations. New York: Wiley, 1958.

Hoiberg, B. C., \& Stires, L. K. The effect of several types of pretrial publicity on the guilt attributions of simulated jurors. Journal of Applied Social Psychology, 1973, 3, 267-275.

Mitchell, H. E., \& Byrne, D. The defendant's dilemma: Effects of jurors' attitudes and authoritarianism on judicial decisions. Journal of Personality and Social Psychology, 1973, 25, 123-129.

ROKEACH, M., \& Vidmar, N. Testimony concerning possible jury bias in a Black Panther murder trial. Journal of Applied Social Psychology, 1973, 3, 19-29.

\section{NOTE}

1. A total of 12 subjects did not assign a prison sentence. These subjects were distributed as follows: one killer-no mutilation, 4; one killer-mutilation, 3; five killers-no mutilation, 3; five killers-mutilation, 2. These subjects were not included in the analysis of assignment of prison sentence. However, these subjects did complete all of the other ratings, and their data were included in the analyses of those ratings.

(Received for publication June 11, 1975.) 